\title{
Infecções micóticas e bacterianas em lesões cutâneas de cães parasitologicamente positivos para Leishmania chagasi
}

\section{Fungal and bacterial infections in skin lesion of dogs naturally infected with Leishmania chagasi}

\author{
Milena de Paiva Cavalcanti, ${ }^{*}$ Maria Aparecida da Gloria Faustino, ${ }^{* *}$ Leucio Câmara Alves, ${ }^{* *}$ \\ Mônica Amorim da Costa Borba, ${ }^{*}$ Leonildo Bento Galiza da Silva, ${ }^{* * *}$ Rinaldo Aparecido Mota**
}

\begin{abstract}
Resumo
Este trabalho teve como objetivo verificar a ocorrência de infecção cutânea fúngica e bacteriana em cães parasitologicamente positivos para leishmaniose visceral canina (LVC). Para o diagnóstico da LVC foram realizados raspados de pele íntegra e/ou lesionada, punção de medula óssea e punção aspirativa de linfonodo poplíteo, utilizando-se 46 animais. Paralelamente foi coletado material para cultura fúngica e bacteriana. Obteve-se $23,91 \%$ de positividade para LVC, sendo $90,90 \%$ dos casos diagnosticados por punção de medula óssea, 45,45\% por raspado de pele íntegra e 36,36\% através de raspado de pele lesionada. Observou-se que associadas às lesões de LVC, ocorreram concomitantemente infecções fúngicas (66,66\%) e bacterianas (100\%), predominantemente por Aspergillus sp. e Staphylococcus sp. respectivamente.
\end{abstract}

Palavras-chave: leishmaniose visceral canina, lesão de pele, fungos, bactérias.

\begin{abstract}
The purpose of this study was to verify the occurrence of fungal and bacterial skin infections in dogs with canine visceral leishmaniasis (CVL). A total of 46 dogs were analised by microscopical examinations of healthy and/or lesioned skin scrapings, puncture of bone marrow, aspirates of a lymphnode for diagnosis of CVL and cutaneous material was collected for fungal and bacterial culture. Index of $23.91 \%$ of the dogs were positive to CVL, being $90.90 \%$ of these cases diagnosed by the examination of the bone marrow material, $45.45 \%$ by healthy skin scrapings and $23.91 \%$ by lesioned skin scrapings. Fungal (66.66\%) and bacterial (100\%) infections, with predominance of Aspergillus sp. and Staphylococcus sp. were associated with the CVL lesions.
\end{abstract}

Keywords: canine visceral leishmaniasis, skin lesion, fungus, bacterium.

\section{Introdução}

Os protozoários do gênero Leishmania são parasitas intracelulares de macrófagos no homem, no cão e em uma variedade de animais silvestres (Urquhart et al., 1990). Foram descritos pela primeira vez por Ross em 1903, e pertencem à ordem Kinetoplastida e família Trypanosomatidae (Losos, 1986). Atualmente existem dois grandes grupos de Leishmania: I - grupo responsável pela leishmaniose tegumentar (cutânea, mucocutânea e cutânea difusa), ocorrendo no cão as espécies Leishmania braziliensis e $L$. tropica, existindo no Brasil apenas L. braziliensis; II - grupo responsável pela leishmaniose visceral ou calazar, onde encontram-se os protozoários do complexo Leishmania donovani, havendo no Brasil apenas L. chagasi (Urquhart et al., 1990; Feitosa et al., 2000).

A leishmaniose visceral é uma antropozoonose caracterizada por infecção generalizada do Sistema Fagocítico Mononuclear (SFM) de mamíferos, transmitida por vetores artrópodes, principalmente da espécie Lutzomyia longipalpis (Ramos et al., 1994; Santa Rosa e Oliveira, 1997; Pocai et al., 1998; Feitosa et al., 2000). Relatada como uma doença silvestre ou de área rural, nos últimos anos este quadro vem-se invertendo devido às alterações ambientais e à migração de um vasto contingente populacional do campo para as cidades. No ambiente doméstico, o cão é considerado o principal reservatório epidemiológico, o que gera dificuldades no controle da doença (Santa Rosa e Oliveira, 1997).

A enfermidade se apresenta como um importante problema de saúde pública, ocorrendo de forma endêmica em diversas regiões do mundo (Badaró e Duarte, 1977 citados por Alves et al., 1998). No Brasil, encontra-se disseminada em 19 estados da Federação, sendo a região Nordeste a principal zona endêmica da leishmaniose visceral nas Américas (Acha e Szyfres, 1986; Monteiro et al., 1994 citados por Alves et al., 1998).

As manifestações clínicas são bastante variadas. Losos (1986) afirma que a enfermidade inicia-se com lesões na pele. Thomé (1999) relata a presença de nódulos cutâneos que, eventualmente, podem ulcerar. Pocai et al. (1998) citam que, nos casos onde há ulcerações, elas são vistas na pele do focinho, orelhas e mucosas oral e nasal. Segundo Feitosa et al. (2000), em 68\% dos casos de LVC, ocorrem alterações dermatológicas, podendo, o animal afetado, apresentar um

\footnotetext{
* Mestranda em Ciência Veterinária - DMV/UFRPE, e-mail: milena.cavalcanti@bol.com.br.

** Prof. adjunto - DMV/UFRPE.

${ }^{* * *}$ Prof. assistente - DMV/UFRPE, Rua Dom Manuel de Medeiros, s/n - Dois Irmãos - CEP 52171-900, Recife, PE, Brasil.
} 
quadro clínico caracterizado por alopecia local ou generalizada, lesões crostosas em geral no focinho, orelhas e nas extremidades, descamação furfurácea, entre outros sinais.

Para o diagnóstico da LVC, entre os exames imunológicos, destacam-se as técnicas de fixação do complemento, imunofluorescência indireta, aglutinação direta e o ensaio imunoenzimático (Elisa). A imunofluorescência indireta tem sido o método mais comumente utilizado, e embora apresente menor sensibilidade e especificidade que o Elisa (Acha e Szyfres, 1986), baseada em critérios técnicos e financeiros, é a prova adotada pela Fundação Nacional de Saúde (FNS).

As provas parasitológicas, que são mais freqüentemente utilizadas como diagnóstico definitivo, incluem a punção aspirativa do baço, do fígado, de linfonodos, da medula óssea, biópsia de órgãos linfóides, isolamento em meio de cultura, entre outros, existindo, ainda, a prova biológica que consiste na inoculação intraperitoneal do material suspeito em hamsters (Mesocricetus auratus) (Urquhart et al., 1990; Corrêa e Corrêa, 1992; Thomé, 1999). Os esfregaços de sangue podem ser examinados, no entanto, apenas eventualmente serão encontradas leishmanias em macrófagos circulantes. É possível, também a identificação de Leishmania no líquido sinovial (Acha e Szyfres, 1986; Merck, 1991; Corrêa e Corrêa, 1992; Feitosa et al., 2000; Klein et al., 2000).

Apesar das alterações dermatológicas observadas nos casos da doença, não há na literatura relatos específicos de infecção fúngica e/ou bacteriana em lesões cutâneas da LVC. Assim, este trabalho tem como objetivo avaliar a presença de infecção fúngica e bacteriana nas lesões cutâneas provocadas pela leishmaniose visceral canina, uma vez que uma terapêutica aleatória pode contribuir para aumentar a disseminação da doença tornando-se prejudicial à saúde pública.

\section{Material e métodos}

Foram utilizados 46 cães procedentes da cidade do Recife e Região Metropolitana, com raças e idades variadas, sendo 24 machos e 22 fêmeas. Após passarem por uma avaliação clínica no Hospital Veterinário da Universidade Federal Rural de Pernambuco, ou serem encaminhados por clínicos particulares, os animais com suspeita de leishmaniose visceral canina foram direcionados ao Laboratório de Doenças Parasitárias dos Animais Domésticos - Departamento de Medicina Veterinária (DMV) da mesma instituição, onde foram preenchidas fichas de identificação contendo dados sobre os proprietários e informações epidemiológicas do calazar. Realizou-se a avaliação física dos animais com a finalidade de observar sinais clínicos da enfermidade, coletando-se, posteriormente, material para diagnóstico parasitológico da LVC, análise fúngica e bacteriana. Para o procedimento de coleta de material, os animais foram contidos com mordaças de náilon adequadas para cada porte, não sendo necessária contenção química.

Para o diagnóstico parasitológico da LVC foram realizados raspados de pele íntegra e/ou lesionada na região do focinho e orelhas, ou quaisquer outras áreas lesionadas com o auxílio de lâmina de bisturi. Do material obtido foram confeccionados esfregaços em lâminas para microscopia, que, após secarem, foram fixados com álcool metílico, corados pelo método de Giemsa ou Panótico e examinados em microscópio óptico com objetiva de imersão. Ainda para o mesmo fim, após antisepsia do local, foi realizado aspirado de medula óssea na crista do osso esterno e aspirado do linfonodo poplíteo, utilizando-se, respectivamente, seringa descartável com capacidade para 20 mililitros $(\mathrm{mL})$, acoplada a agulha tamanho $40 \times 12 \mathrm{~mm}$ e agulha hipodérmica descartável $25 \times 7 \mathrm{~mm}$, acoplada a uma seringa descartável de $10 \mathrm{~mL}$. Do material puncionado, foram preparados esfregaços em lâminas para microscopia, que foram corados pelo método Panótico e examinados em microscópio óptico com objetiva de imersão.

O material para cultura bacteriana foi coletado através de um swab estéril pressionado sobre a lesão, encaminhado, em seguida, ao Laboratório de Doenças Infecciosas dos Animais Domésticos - DMV - UFRPE. A inoculação foi realizada a partir do swab, sendo o material esgotado com alça de platina em movimentos de estrias, em ágar sangue e, então, incubado a $37^{\circ} \mathrm{C}$ por 24 horas, procedendo-se, em seguida, à leitura e caracterização macroscópica das colônias bacterianas e coloração pelo método de Gram.

Para análise fúngica, foram realizados raspados cutâneos na periferia das áreas lesionadas, os quais foram encaminhados ao Laboratório de Doenças Infecciosas dos Animais Domésticos e semeados em placas de ágar sabouraud, incubado à temperatura ambiente. Evidenciado o crescimento do fungo, foi retirado um fragmento da colônia, colocado em lâmina de vidro, acrescentando-se gotas de azul de algodão, examinando-se, entre lâmina e lamínula, ao microscópio óptico em objetiva de imersão.

\section{Resultados e discussão}

A análise dos exames parasitológicos revelou uma positividade de 23,91\%, (11/46) para LVC e 76,09\% corresponderam a exames negativos. O percentual de positividade ora observado é inferior ao registrado por Mendonça (1997) no Piauí, onde se obteve $50 \%$ de animais positivos, e superior ao apresentado por Gurgel e Pena (1995) no Recife, que obtiveram $17,86 \%$ de amostras positivas.

No total de animais positivos (Tabela 1), a punção de medula óssea mostrou-se ser eficaz em dez dos 11 cães portadores de leishmaniose visceral canina, o equivalente a $90,90 \%$ dos casos, resultado superior ao descrito pela Organização Mundial de Saúde que apresenta valores entre 54 a $86 \%$ de positividade em esfregaços de aspirado medular (Who, 1984). Os resultados estão de acordo com os apresentados por Alencar (1959) e Font et al. (1994) que afirmam ser eficaz e seguro o diagnóstico da leishmaniose canina por este método. A positividade aos raspados de pele íntegra e lesionada foi de $45,45 \%(5 / 11)$ e $36,36 \%$ (4/11) respectivamente. A punção aspirativa do linfonodo poplíteo foi o único exame em que não foram observadas formas amastigotas de Leishmania sp.

A análise fúngica e bacteriana das lesões dos cães positivos foi realizada em seis dos 11 animais (Tabela 2). A análise bacteriana revelou infecção por Staphylococcus sp. em todas as amostras analisadas (6/6), provavelmente por ser este agente um componente da fauna fisiológica da pele (Scott et al., 1996). Foi encontrada associação com Micrococcus sp. em uma das amostras. Na análise fúngica, Aspergillus sp. apresentou predominância, ocorrendo em quatro dos seis animais (4/6), o correspondente a $66,66 \%$ das amostras, havendo uma amostra positiva para Mycelia sp. (1/6), correspondente a $16,16 \%$ e uma amostra negativa (1/6), correspondente a $16,16 \%$. Os agentes micóticos identificados são classificados como organismos saprófitas e representam uma contaminação transitória da pele. Observou-se infecção concomitante por fungos e bactérias em $83,33 \%$ (5/6) das amostras. 
Tabela 1: Positividade para Leishmania spp. em exames parasitológicos realizados em cães atendidos no DMVUFRPE

\begin{tabular}{ccccc}
\hline ANIMAL & MEDULA & $\begin{array}{c}\text { PELE } \\
\text { ÍNTEGRA }\end{array}$ & $\begin{array}{c}\text { PELE } \\
\text { LESIONADA }\end{array}$ & LINFONODO \\
\hline $\mathrm{N}^{\circ} 1$ & - & + & - & - \\
$\mathrm{N}^{\circ} 2$ & + & + & + & $\mathrm{X}$ \\
$\mathrm{N}^{\circ} 3$ & + & - & + & $\mathrm{X}$ \\
$\mathrm{N}^{\circ} 4$ & + & + & + & $\mathrm{X}$ \\
$\mathrm{N}^{\circ} 5$ & + & + & + & $\mathrm{X}$ \\
$\mathrm{N}^{\circ} 6$ & + & - & - & $\mathrm{X}$ \\
$\mathrm{N}^{\circ} 7$ & + & + & $\mathrm{X}$ & $\mathrm{X}$ \\
$\mathrm{N}^{\circ} 8$ & + & - & - & $\mathrm{X}$ \\
$\mathrm{N}^{\circ} 9$ & + & - & - & - \\
$\mathrm{N}^{\circ} 10$ & + & - & - & - \\
$\mathrm{N}^{\circ} 11$ & + & - & - & - \\
$\%$ & 90,90 & 45,45 & 36,36 & 0 \\
\hline
\end{tabular}

- Resultado negativo, + Resultado positivo, X Exame não realizado.

Apesar de as bactérias e fungos isolados das lesões cutâneas do calazar serem componentes normais ou contaminantes saprófitas da fauna cutânea, em situaçães favoráveis ao seu desenvolvimento, podem tornar-se agentes etiológicos de uma dermatite bacteriana ou fúngica, respectivamente. Este resultado confirma dados apresentados por Feitosa et al. (2000) que relatam a possibilidade de ocorrência de outras infecções cutâneas associadas ao quadro de leishmaniose.

\section{Referências}

ACHA, P. N.; SZYFRES, B. Zoonosis y enfermedades transmisibles comunes al hombre y a los animales. 2. ed. Washington: Organización Panamericana de la Salud, 1986.

ALENCAR, J. E. Calazar canino. Contribuição para o estudo da epidemiologia do calazar no Brasil. 1959. 342 f. Tese (Mestrado)Universidade Federal do Ceará, 1959.

ALVES, A. L. et al. Levantamento epidemiológico da leishmaniose visceral em cães vadios da cidade de Fortaleza, Ceará. Ciência Animal, v. 8, n. 2, p. 63-67, 1998.

CORRÊA, W. M.; CORRÊA, C. N. M. Enfermidades infecciosas dos mamíferos domésticos. 2. ed. Rio de Janeiro: MEDSI. 1992.

FEITOSA, M. M. et al. Aspectos clínicos de cães com leishmaniose visceral no município de Araçatuba - São Paulo (Brasil). Clínica Veterinária, Ano V, n. 28, p. 36-42, 2000.

FONT, A. et al. Monoclonal gammopaty in dog with visceral leishmaniasis. J. of Vet. Internal. Méd., v. 8, n. 3, p. 233-235, 1994.

GURGEL, A. E. B.; PENA, E. J. M. Diagnóstico da Leishmaniose visceral canina através de IFI e exames parasitológicos em cães da região metropolitana do Recife. CONGRESSO DE INICIAÇÃO CIENTÍFICA DA UNIVERSIDADE FEDERAL RURALDEPERNAMBUCCANO, 5., 1995, Anais ..., 1995. p. 144

KLEIN, R. P. et al. Detecção de leishmanias no sangue periférico de cães com leishmaniose visceral. JORNADA PAULISTA DE PARASITOLOGIA, 13., 2000, Anais .., 2000. p. 41.
Tabela 2: Análise fúngica e bacteriana em raspados de pele e swabs de lesões cutâneas de cães parasitologicamente positivos para Leishmania sp., atendidos no DMV-UFRPE

\begin{tabular}{cll}
\hline ANIMAL & \multicolumn{1}{r}{$\begin{array}{r}\text { CULTURA } \\
\text { FÚNGICA }\end{array}$} & \multicolumn{1}{c}{ CULTURA BACTERIANA } \\
\hline $\mathrm{N}^{\circ} 1$ & Aspergillus sp. & Staphylococcus sp. \\
$\mathrm{N}^{\circ} 2$ & Aspergillus sp. & Staphylococcus sp. \\
$\mathrm{N}^{\circ} 3$ & Aspergillus sp. & Staphylococcus sp./ Micrococcus sp. \\
$\mathrm{N}^{\circ} 4$ & $\mathrm{X}$ & $\mathrm{X}$ \\
$\mathrm{N}^{\circ} 5$ & Mycelia sp. & Staphylococcus sp. \\
$\mathrm{N}^{\circ} 6$ & $\mathrm{X}$ & $\mathrm{X}$ \\
$\mathrm{N}^{\circ} 7$ & $\mathrm{X}$ & $\mathrm{X}$ \\
$\mathrm{N}^{\circ} 8$ & $\mathrm{X}$ & $\mathrm{X}$ \\
$\mathrm{N}^{\circ} 9$ & Aspergillus sp. & Staphylococcus $\mathrm{sp}$. \\
$\mathrm{N}^{\circ} 10$ & - & Staphylococcus $\mathrm{sp}$. \\
$\mathrm{N}^{\circ} 11$ & $\mathrm{X}$ & $\mathrm{X}$ \\
\hline
\end{tabular}

- Resultado negativo, X Não foi realizado.

\section{Conclusão}

Infecções micóticas e bacterianas podem estar freqüentemente associadas às lesões cutâneas de cães com LVC fato a ser levado em consideração no diagnóstico diferencial das dermatopatias infecciosas caninas.

LOSOS, G.J. Infectious tropical diseases of domestic animals. Canadá: International Development Research Centre, 1986.

MENDONÇA, I. L. Avaliação do uso da eletroforese em acetato celulose como método auxiliar no diagnóstico da leishmaniose visceral canina. 1997. 47 f. Tese (Mestrado)-Universidade Federal Rural de Pernambuco, 1997.

MERCK. Manual Merck de Veterinária. 7. ed. São Paulo: Roca, 1991. POCAI, E. A. C. et al. Visceral leishmaniasis (Kala-azar). Five cases in Santa Maria, Rio Grande do Sul, South Brazil. Ciência Rural, v. 28, n. 3, p. 501-505, 1998.

RAMOS, G. P. et al. Valores bioquímicos-séricos de cães portadores de leishmaniose visceral. Revista Brasileira de Medicina Veterinária, v. 16, n. 5, p. 192-196. 1994.

SANTA ROSA, I. C. A.; OLIVEIRA, C. S. O. Leishmaniose visceral: breve revisão sobre uma zoonose reemergente. Clínica Veterinária, Ano 2, n. 11, p. 24-28, 1997.

SCOTT, D. W.; MILLER JR., W. H.; GRIFFIN, C. E. Muller \& Kirk. Dermatologia de pequenos animais. 5. ed. Rio de Janeiro: Interlivros, 1996.

THOMÉ, S. M. G. Cuidado com as leishmanioses. Cães \& Gatos, Ano 14, n. 85, p. 46-50, 1999.

URQUHART, G. M. et al. Parasitologia Veterinária. Rio de Janeiro: Guanabara Koogan, 1990.

WORLD HEALTHY ORGANIZATION. Control of leishmaniasis. Who Technical Report Series, 701, WHO, Geneva, 1984. 